\title{
The lab that asked the wrong questions
}

\section{PRINCETON}

A medley of random-event machines, including a kaleidoscopic crystal ball on a pendulum, a pipe spurting water and a motorized box straddled by a toy frog, came to the end of their working lives yesterday at the Princeton Engineering Anomalies Research (PEAR) laboratory in New Jersey.

Only romantics - and some parapsychologists - are likely to lament the loss of this unique institution, which investigated whether people can alter the behaviour of machines using their thoughts. Many scientists think the lab's work was pointless at best. But the closure highlights a long-running question: how permissive should science be of research that doesn't fit a standard theoretical framework, if the methods used are scientific?

The PEAR lab was founded in 1979 by Robert Jahn, former dean of Princeton's school of engineering and applied sciences, and an expert on electric propulsion. Start-up funds came from aerospace pioneer James McDonnell, who believed that aircraft machinery was influenced by the mental states of pilots. The lab has relied on private funds ever since.

Over 28 years, PEAR researchers collected data from tens of millions of trials using random-event machines. When all the data are considered together, they show that human intention has a very slight effect, the researchers say. Whether the machine is a screen that flashes numbers or a fountain of water droplets, they say that, on average, people can shift $2-3$ events out of 10,000 from chance expectations.

It was Jahn's decision to close the lab. He set

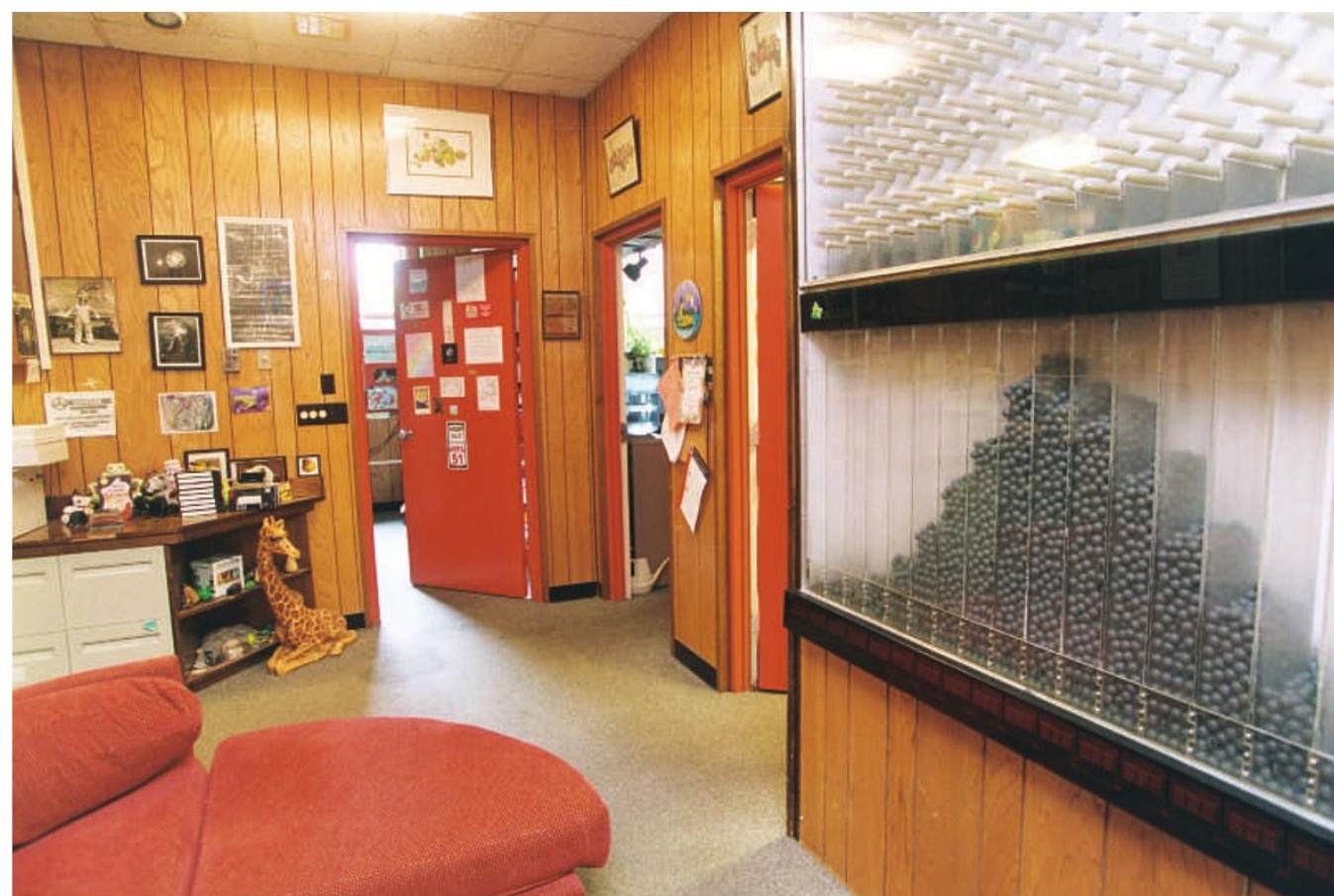

PEAR lab researchers feel that their parapsychology work was unfairly judged.

out to prove the existence of the effect and, at 76 , believes the work is done. But such tiny deviations from chance have not convinced mainstream scientists, and the lab's results have been studiously ignored by the wider community. Apart from a couple of early reviews (R. G. Jahn Proc. IEEE 70, 136-170; 1982 and R. G. Jahn and B. J. Dunne Found. Phys. 16, 721-772; 1986), Jahn's papers were rejected from main- stream journals. Jahn believes he was unfairly judged because of the questions he asked, not because of methodological flaws.

Even in other areas of parapsychology, opinion is divided on the lab's results. The difficulty is that it's virtually impossible to prove that such subtle effects aren't caused by some flaw in the methods or equipment. A recent meta-analysis (H. Bösch et al. Psychol. Bull. 132, 497-523;

\section{Data sharing: the next generation}

The Internet has already become a place for people to share knowledge, opinions, music and videos. Now, in a slightly geekier aspect of the same trend, social software is allowing people to share data too. More than 1 million data sets have been uploaded to the data-sharing site Swivel since its launch in December. And on 23 January, IBM labs launched Many Eyes, which allows users to visualize their data with tools previously available only to experts.

Once data are uploaded to these sites (which are still being tested), people can reanalyse the numbers, mix them with other data and visualize them in different ways. Swivel focuses on letting users combine data sets, with some basic ways to present the results such as scatter graphs and bar charts. Many Eyes allows users to generate more complicated graphs such as network diagrams, which depict nodes and connections within networks, and treemaps, which display data as groups of nested rectangles.

The idea is to make data analysis more democratic, as tools such as Google Earth have done for geographic visualization, says Fernanda Viégas of IBM's Visual Communication Lab in Cambridge, Massachusetts. "We want to provide the masses with access to visualization tools, especially interactive ones," she says.

Governments, international agencies and research organizations generate huge silos of publicly available data on almost every aspect of society, but the public has never been able to explore, share and discuss these data sets easily, she points out.

Making such tools available will not only empower individuals, Viégas predicts, the collective intelligence and expertise of users will result in new insights. "Just three weeks in, people were using some of the most sophisticated visualization types," she says. Since Many Eyes launched, users have uploaded data and created graphics on everything from the stock price of Heineken against temperature, to collaborations of prostate cancer researchers, to co-occurrences of 
2006) combined 380 studies on the phenomenon, often termed psychokinesis, including data from the PEAR lab. It concluded that although there is a statistically significant overall effect, it is not consistent and relatively few negative studies would cancel it out, so biased publication of positive results could be the cause.

Robert Park, a physicist at the University of Maryland, adds that if you run any test often enough, it's easy to get the "tiny statistical edges" the PEAR team seems to have picked up. If a coin is flipped enough times, for example, even a slight imperfection can produce more than $50 \%$ heads.

In the end, the decision whether to pursue a tiny apparent effect or put it down to statistical flaws is a subjective one. "It raises the issue of where you draw the line," says sceptic Chris French, an 'anomalistic psychologist' at Goldsmiths, University of London, who tries to explain what seem to be paranormal experiences in straightforward psychological terms. French thinks that even though the chances of a real effect being discovered are low, the implications of a positive result would be so interesting that work such as Jahn's is worth pursuing.

Many scientists disagree. Besides being a waste of time, such work is unscientific, they argue, because no attempt is ever made to offer a physical explanation for the effect. Park says the PEAR lab "threatened the reputation" of both Princeton and the wider community. $\mathrm{He}$ sees the persistence of such labs as an unfortunate side effect of science's openness to new questions. "The surprising thing is that it doesn't happen more often," he says.

William Happer, a prominent physicist at Princeton, takes the middle ground. $\mathrm{He}$ believes the scientific community should be open to research that asks any question, however unlikely, but that if experiments don't produce conclusive results after a reasonable time, researchers should move on. "I don't know why this took up a whole lifetime," he says.

The status of paranormal research in the United States is now at an all-time low, after a relative surge of interest in the 1970s. Money continues to pour from philanthropic sources to private institutions, but any chance of credibility depends on ties with universities, and only a trickle of research now persists in university labs.

Elsewhere the field is livelier. Britain is a lead player, with privately funded labs at the universities of Edinburgh, Northampton and Liverpool Hope, among others. Parapsychologist Deborah Delanoy at the University of Northampton suspects that the field is stronger in Britain because researchers tend to work in conventional psychology departments, and also do studies in 'straight' psychology to boost their credibility and show that their methods are sound. "We're seen to be in the same business as other psychologists," she says.

But parapsychologists are still limited to publishing in a small number of niche journals. French thinks the field is treated unfairly. "I'm convinced that parapsychologists have a hard time trying to publish in mainstream journals," he says, adding that he even has difficulty publishing his 'straight' papers on why people believe in paranormal events: "Simply because the paper mentions the word telepathy or psychokinesis, it isn't sent out to referees. People think the whole thing is a waste of time."

Lucy Odling-Smee names in the New Testament.

The new sites might also provide a model for better communication among scientists, says Brent Edwards, director of the Starkey Hearing Research Center in Berkeley, California, who blogs on innovation in science. He points out that journals could use the Internet to share information and move science forward much more effectively, rather than being facsimiles of their print cousins, with static graphs and figures.

"I'm often frustrated by my inability to analyse in a different way data that are printed in peer-reviewed publications, when I'm interested in looking at a relationship that the authors didn't think of," he says. If research organizations and journals linked the raw data behind papers to social software tools such as Swivel and Many Eyes, he argues, "it would have considerable value to the scientific community as a whole".

David Lipman, director of the US National Center for Biotechnology Information in Bethesda, Maryland agrees, adding that his centre might explore related possibilities. He finds it ironic that scientists have been slow to adopt social software, given how useful it could be for them. "Scientists are more interested in their careers and grants than using tools that promote better communication and data sharing," Lipman says.

He's optimistic that this attitude may change in the future, however, especially as a new generation - used to communicating through social sites such as MySpace - enters research.

Declan Butler
SCORECARD

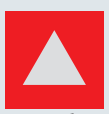

Australian lightbulbs Australia, yet to sign the Kyoto Protocol, has boosted its green credentials by pledging to replace all conventional lightbulbs with energyefficient ones.

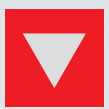

\section{DVD games} A new game called Body Mechanics aims to teach kids about healthy lifestyles by battling the evil Col Esterol and his cronies while sitting in front of the television.

\section{ON THE RECORD}

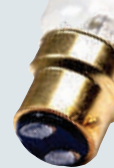

\section{“Red hot .... Better performance. Better price.》}

The caption accompanying a picture of a scantily clad female model featured in an advert for optical company Edmund Optics. Offended scientists of both sexes have accused the firm of insulting the scientific community.

\section{(CI always knew that a geek would make a great husband.”}

Minneapolis resident Melinda Kimberly, who retrieved her stolen laptop because her husband was using it to run the alien-hunting SETI@home software. The program revealed the laptop's location when it checked in with SETI's server.

\section{NUMBER CRUNCH}

\section{$£ 18,000$ (roughly}

US $\$ 35,000$ ) was spent by the UK Ministry of Defence in 2002 to investigate the potential use of psychic powers to detect hidden objects.

12 self-proclaimed psychics declined to participate in the research, meaning the ministry had to rely on novice volunteers.

1 participant fell asleep during the study, which ultimately concluded that psychic techniques are of "little value".

Sources: news.com.au, Associated Press, CosmicVariance, BBC 